\title{
Hepatic veno-occlusive disease in children after hematopoietic stem cell transplantation
}

\author{
Kris M. Mahadeo ${ }^{\mathrm{a}}$ and Rajinder P.S. Bajwa ${ }^{\mathrm{b}, *}$ \\ ${ }^{a}$ Pediatric Blood and Marrow Transplantation, Children's Hospital, Montefiore Albert Einstein College of Medicine, \\ New York, NY, USA \\ ${ }^{\mathrm{b}}$ Department of Hematology/Oncology/BMT, Nationwide Children's Hospital, Columbus, OH, USA
}

Received 2 August 2014

Revised 22 August 2014

Accepted 2 September 2014

\begin{abstract}
Hepatic veno-occlusive disease (VOD), or sinusoidal obstruction syndrome, is a potentially fatal complication, which occurs in $7-27 \%$ of children undergoing hematopoietic stem cell transplantation. In this article, we review commonly accepted diagnostic criteria, atypical diagnostic features as well as preventative and treatment measures associated with VOD. Reversal of portal venous flow by Doppler ultrasound is often a late finding; many patients with anicteric VOD may never develop hyperbilirubinemia, and yet perish from severe VOD. Transjugular liver biopsy is usually not available and/or is often avoided. Prophylactic therapies with ursodeoxycholic acid, heparin and defibrotide are discussed. Supportive care with fluid restriction and diuretic therapy, analgesia, blood and platelet transfusions, paracentesis as well as other pulmonary and renal therapies remain imperative to superior outcomes. Specific therapy with thrombolytics such as defibrotide and recombinant tissue plasminogen activator is discussed and a classification of severity of VOD is proposed.
\end{abstract}

Keywords: Hepatic veno-occlusive disease, portal venous flow, plasminogen activator

\section{Introduction}

Hepatic veno-occlusive disease (VOD), or sinusoidal obstruction syndrome, is a potentially fatal complication, associated with hematopoietic stem cell transplantation (HSCT) [1-4]. The diagnosis of VOD is based on clinical findings and there is no consensus on the grading of severity. Prompt diagnosis and intervention is important as severe VOD has a poor prognosis. Most patients with severe VOD develop multi-organ failure (MOF), requiring admission to the intensive care unit and care by a multi-specialty team. The purpose of this review is to focus primarily on the

\footnotetext{
*Corresponding author: Dr. Rajinder P.S. Bajwa, Nationwide Children's Hospital, Department of Hem/ONC/BMT, 700 Children's drive, Columbus, $\mathrm{OH}$ 43205, USA. Tel.: +1 6147223582; Fax: +1 6147223699; E-mail: Rajinder.Bajwa@nationwidechildrens.org.
}

early diagnosis and management of pediatric aspects of VOD. The term VOD will be used in this manuscript.

\section{Epidemiology and risk factors}

Approximately 20,000 patients undergo HSCT annually in the United States; one tenth of these cases are pediatric. The reported incidence of VOD among pediatric HSCT recipients is $7-27 \%$ and approximately $20 \%$ of these cases are severe; a higher prevalence, as much as $70 \%$, is reported in some adult series [5-8].

Pre-existing liver disease is the single most important risk factor for the development of VOD. Hepatic iron overload and hepatic dysfunction secondary to chemotherapy after myelotarg (gemtuzumabozogamicin) increases the risk of VOD [9]. A younger 
age of less than $6 \mathrm{mo}$ in one series and $<6.7 \mathrm{yr}$ in another has been associated with an increased risk of VOD [5, 10]. Myeloablative preparative regimens using busulfan with cyclophosphamide and cyclophosphamide with total body irradiation are also associated with increased risk of VOD [11]; while reduced intensity conditioning or non-myeloablative regimens for HSCT are associated with a lower risk of VOD [12]. Recently, treosulfan (L-treitol-1, 4-bis-methanesulfonate) based regimens have been found to be associated with low rates of VOD [13]. Sirolimus for graft versus host disease (GvHD) prophylaxis has been associated with an increased incidence of VOD [14]. The risk of VOD is also increased during HSCT for osteopetrosis, hemophagocytic lymphohistiocytosis or second transplant. Genetic polymorphisms of glutathione-Stransferase, tumor necrosis factor- $\alpha$ and thiopurine methyltransferase in the recipient and of interleukin- $1 \beta$ in the donor have been associated with $\operatorname{VOD}[15,16]$.

\section{Pathophysiology}

VOD is believed to occur as a result of toxic injury to the hepatic sinusoidal cells and hepatocytes in the liver acinus, leading to the formation of occlusive thrombotic clots in the sinusoids, obstructing the flow of blood from the portal and hepatic veins to the central vein. Endothelial injury, cytokine mediated inflammation and complement may have a role in the pathogenesis [12-18]. Von Willebrand factor, thrombomodulin, E-selectin, and soluble intercellular adhesion molecule-1 were elevated as markers of endothelial injury in patients who developed VOD in conjunction with sirolimus therapy [17]. Several studies have found that plasminogen activator inhibitor-1 levels are elevated in VOD; these levels may also predict severity [18-20]. Lower a disintegrin and metalloproteinase with a thrombospondin type 1 motif, member 13 (ADAMTS13) also known as von Willebrand factorcleaving protease 13 activity was found in patients with VOD and later the same group found lower rates of VOD in patients who were given prophylactic fresh frozen plasma (FFP) infusions during HSCT [21, 22]. Similarly studies have also shown a lower mean minimum protein-C activity in patients with VOD compared to that in patients without VOD $(P<0.0001)[23,24]$.

The clinical features of VOD are the result of pathophysiology similar to that of portal hypertension combined with a capillary leak syndrome secondary to the conditioning regimen. This combination leads to extravasation of fluids (edema, ascites and pleural/ pericardial effusions), weight gain and depletion of the intravascular volume. As ascites worsens, increased intra-abdominal pressure is reflected on the diaphragm contributing to pulmonary dysfunction. The increased intra-abdominal pressure may also lead to decreased renal perfusion by direct pressure on the renal vasculature.

\section{Clinical features and diagnosis}

The diagnosis of VOD is based on clinical features of hyperbilirubinemia, fluid retention and hepatomegaly. Weight gain, inability to maintain platelet counts above $20,000 / \mathrm{mm}^{3}$ in spite of frequent transfusions and increased opioid requirements for pain control are indirect indicators suggestive of VOD. Tender hepatomegaly may be difficult to elicit in children due to their lack of cooperation with physical exam. The two widely used diagnostic criteria: i) the Baltimore criteria and ii) the modified Seattle criteria are described in Table $1[3,4,25]$. The Baltimore criteria appear to be more stringent as patients without hyperbilirubinemia are excluded. On the other hand, the modified Seattle criteria may lead to over diagnosis as some patients may satisfy the diagnostic criteria solely due to fluid overload. While liver biopsy is helpful for confirming the diagnosis, in the setting of thrombocytopenia and increased bleeding risk, this is usually avoided.

Although it has been nearly two decades since these criteria were initially proposed, the severity of VOD is still not uniformly defined. Bearman et al. [26] proposed a retrospective definition of severity, in which patients who died were considered to have severe VOD, patients who required treatment in the form of fluid restriction and diuretics and then recovered had moderate VOD, and patients who required no treatment

Table 1

Diagnostic criteria for veno-occlusive disease

Criteria
Modified Seattle criteria
At least two of the following occurring within 20 days of
hematopoietic stem cell transplantation
Bilirubin $\geq 2 \mathrm{mg} / \mathrm{dL}$
Ascites and/or unexplained weight gain of $>2 \%$ from baseline
Hepatomegaly and right upper quadrant pain
Baltimore criteria
Bilirubin $\geq 2 \mathrm{mg} / \mathrm{dL}$ and any two of the following criteria
Hepatomegaly
Weight gain $>5 \%$ of baseline
Ascites


or had a self-limiting disease had mild VOD. Because of the retrospective nature of this grading, it was not helpful in guiding therapy for patients with VOD. Bearman et al. [26] also developed a logistic regression model for predicting the probability of developing severe VOD based on the percentage of weight gain and the total serum bilirubin from days -1 to +16 after HSCT. This model was found to be highly specific, but had low sensitivity and only identified patients with severe VOD. The model also did not take into account patients with anicteric VOD who can have an equally severe clinical course without an increase in bilirubin. A proposed severity classification for VOD has been presented in this review based on the degree of platelet refractoriness, continued weight gain, worsening ascites, and the presence or absence of organ dysfunction (Table 2). Pulmonary dysfunction is defined as a documented oxygen saturation of $<90 \%$ in room air (measured twice) or the need for assisted ventilation. Renal dysfunction is defined as doubling of the serum creatinine from baseline, a glomerular filtration rate $<40 \%$ from baseline, and/or the need for dialysis/renal replacement therapy. Cardiac dysfunction is defined as the need for vasopressors to maintain normal blood pressures.

\subsection{Anicteric VOD}

The diagnosis of VOD is often difficult, unless the patient has hyperbilirubinemia. In addition, the severity of VOD is often gauged by the degree of hyperbilirubinemia. However, a HSCT patient who has hepatomegaly and weight gain, but without an increase of bilirubin, is still likely to have VOD provided other differential diagnoses have been excluded. Such patients meet the Seattle criteria for the diagnosis of VOD. In a retrospective review of 30 patients with a diagnosis of VOD in children, Naples (personal communication) found $9 / 29$ of the patients had a maximum bilirubin of $<2 \mathrm{mg} / \mathrm{dL}$ during the entire course of diagnosis and treatment for VOD and 2/29 of these patients died due to MOF. Such patients with anicteric VOD should not be considered as having mild or moderate VOD merely because they have no increase of bilirubin and treatment should be initiated as soon as anicteric VOD is diagnosed.

\section{Investigations}

\subsection{Imaging}

The role of ultrasound in the diagnosis of VOD has been well studied; grey scale assessment of the liver, thickening of the gall bladder, presence of ascites, flow velocity profiles in the left, right and main portal veins and the hepatic artery resistive index (RI) have all been assessed [27, 28]. In a prospective study, RI values were found to be significantly elevated in patients with VOD, although they did not correlate with portal venous flow and VOD [29]. The hepatic artery RI was

Table 2

Proposed classification of severity of veno-occlusive disease in children

\begin{tabular}{|c|c|c|c|}
\hline & Mild* veno-occlusive disease & Moderate* veno-occlusive disease & Severe* veno-occlusive disease \\
\hline \multicolumn{4}{|c|}{ Clinical features } \\
\hline & Patient has veno-occlusive disease & $\begin{array}{l}\text { Patient has mild veno-occlusive disease } \\
\text { and }\end{array}$ & $\begin{array}{l}\text { Patient has moderate veno-occlusive disease } \\
\text { and }\end{array}$ \\
\hline & No pulmonary or renal dysfunction & No renal dysfunction & Pulmonary and or renal dysfunction present \\
\hline & Anicteric/hyperbilirubinemia & $\begin{array}{l}\text { Anicteric/may have rapidly rising } \\
\text { bilirubin }\end{array}$ & $\begin{array}{l}\text { Anicteric/may have very rapidly rising } \\
\text { bilirubin }\end{array}$ \\
\hline & $\begin{array}{l}\text { No need for oxygen } \\
\text { supplementation }\end{array}$ & $\begin{array}{l}\text { Has worsening ascites causing } \\
\text { dyspnea, may need blow by oxygen }\end{array}$ & Needing assisted ventilation \\
\hline & No need for peritoneal drain & - & Has a peritoneal drain in place \\
\hline & $\begin{array}{l}\text { Requires platelet transfusions }<2 \\
\text { times a day to keep platelets } \\
>20,000 / \mathrm{mm}^{3}\end{array}$ & $\begin{array}{l}\text { Requires platelet transfusions }>2 \text { times } \\
\text { a day to keep Platelets }>20,000 / \mathrm{mm}^{3}\end{array}$ & $\begin{array}{l}\text { Requires platelet transfusions }>2 \text { times a day } \\
\text { to keep platelets }>20,000 / \mathrm{mm}^{3}\end{array}$ \\
\hline & Weight gain $<5 \%$ from baseline & $\begin{array}{l}\text { Weight gain } 5-10 \% \text { from baseline } \\
\text { despite diuretics }\end{array}$ & $\begin{array}{l}\text { Weight gain }>10 \% \text { from baseline despite } \\
\text { diuretics }\end{array}$ \\
\hline \multicolumn{4}{|l|}{ Treatment } \\
\hline & Supportive care, close monitoring & $\begin{array}{l}\text { Consider peritoneal drain, start specific } \\
\text { therapy, augment supportive care, } \\
\text { consider continuous venovenous } \\
\text { hemofiltration and continue close } \\
\text { monitoring }\end{array}$ & $\begin{array}{l}\text { Continue peritoneal drain, continue specific } \\
\text { therapy, maximize supportive care, } \\
\text { assisted ventilation, continuous } \\
\text { venovenous hemofiltration, etc. }\end{array}$ \\
\hline
\end{tabular}

*Veno-occlusive disease as defined by modified Seattle criteria [3]. 
0.75 or greater in $95 \%$ of the patients with VOD as compared to the control group $(P<0.01)$ [30]. In other reports, grey scale abnormalities and color Doppler flow assessments failed to demonstrate any benefit over the clinical criteria in the diagnosis of VOD [30, 31]. However, demonstration of reversal of portal venous blood flow by ultrasonography can be helpful, but is often a late finding indicating near total obstruction of the hepatic sinusoids and advanced disease. In a prospective study in children, Lassau et al. [32] performed Doppler examinations at the time of the clinical and biological diagnosis of VOD after HSCT. Patients were given an ultrasound score (US), a Doppler score, and a total Doppler US. The multivariate analysis of the pooled US and Doppler US found that the flow recorded in the para-umbilical vein was the only criterion significantly associated with the grade of VOD $(P=0.0001)$. The role of magnetic resonance imaging and positron emission testing/computerized tomography in the diagnosis of VOD have not been well established limited primarily to case reports [33, 34].

\subsection{Other investigations}

Complete blood cell counts, coagulation profile (including prothrombin time, activated partial thromboplastin time, international normalized ratio, and fibrinogen levels), serum electrolyte levels, blood urea nitrogen and creatinine concentrations, and liver function tests are routinely performed in any unit caring for HSCT patients. Plasminogen activator inhibitor1 levels have been found to be increased in patients with VOD who had hyperbilirubinemia [18-20]; however this is still an area of ongoing research. Similarly markers of endothelial injury as mentioned above in pathophysiology, maybe elevated in patients who developed VOD while on sirolimus [17]. However, there are very few investigations which can help to establish the diagnosis of VOD with certainty. A percutaneous liver biopsy is usually avoided due to the increased risk of bleeding. Trans-jugular liver biopsies offer an option with decreased risk of bleeding as well as the benefit of the measuring hepatic sinusoidal pressure gradient (HSPG). However, this procedure is not available at many pediatric centers. In a recent study of adult subjects undergoing HSCT, a total of 166 trans-jugular biopsies were performed on 161 subjects; nearly all were successful $(99 \%)$. The authors correlated the corrected HSPG with the pathologic diagnoses of VOD and found that a corrected HSPG
$>10 \mathrm{mmHg}$ identified VOD with $90.8 \%$ specificity and $77.3 \%$ sensitivity [35].

\section{Differential diagnosis}

The differential diagnosis of VOD includes i) fluid overload from non-VOD related causes, ii) infections; including viral, fungal and bacterial infections, iii) medications; including hepatotoxicity from voriconazole or other azoles, calcineurin inhibitors and total parental nutrition, iv) acute GvHD; should be considered in the differential diagnosis during the peri-engraftment period and it may be very difficult to exclude without a liver biopsy.

\section{Prophylaxis}

Table 3 summarizes several measures which have been proposed for VOD prophylaxis; Levels of evidence and grading recommendations are also shown for each measure listed [36]. To date, defibrotide and ursodiol prophylaxis have shown the most promising results.

\subsection{Ursodeoxycholic acid (UDCA)}

UDCA administration is believed to replace toxic, hydrophobic bile acids in the liver with nontoxic, hydrophilic bile acids; this results in increased stability of hepatocyte cell membranes and decreased hepatocyte necrosis from damage caused by preparative regimens. A randomized double blinded, controlled study of 67 patients undergoing allogeneic HSCT demonstrated a lower incidence of VOD with UDCA administration versus placebo $(P=0.03)$ [37]. A Japanese prospective, unblinded randomized, multicenter study also suggested that UDCA was effective in preventing VOD. In that trial, VOD occurred in only

Table 3

Veno-occlusive disease prophylactic measures

\begin{tabular}{lcc}
\hline Prophylaxis & $\begin{array}{c}\text { Level of } \\
\text { evidence* }\end{array}$ & $\begin{array}{c}\text { Grade of } \\
\text { recommendation* }\end{array}$ \\
\hline Defibrotide & 1 & $\mathrm{~A}$ \\
Ursodeoxycholic acid & 2 & $\mathrm{~B}$ \\
Heparin & 2 & $\mathrm{C}$ \\
Fresh frozen plasma & 2 & $\mathrm{C}$ \\
Anti-thrombin 3 replacement & 3 & $\mathrm{C}$ \\
\hline
\end{tabular}

*Adapted from Ref.[36]. 
$3.0 \%$ in the UDCA-treated group as opposed to $18.5 \%$ in the control group $(P=0.0043)$ [38]. However, a prospective, randomized, open-label multi-center trial by the Nordic bone marrow transplant group failed to confirm these findings. While they found that UDCA administration was associated with reduced hepatic complications and GvHD, they found no difference in the incidence of VOD [39]. In another trial comparing UDCA and heparin to heparin alone, Park et al. [40] reported no significant difference in the incidence of VOD $(15.9 \%$ versus $19.3 \%, P=0.348)$ or in 100 day survival. Finally, a systematic review of controlled UDCA clinical trials did demonstrate a reduced incidence of VOD among patients receiving UDCA [41]. Consequently, given the low cost and favorable safety profile associated with UDCA administration, this appears to be a reasonable prophylaxis strategy.

\subsection{Heparin}

Unfractionated heparin (UFH) and low molecular weight heparin (LMWH) have been used as prophylaxis for VOD. One phase two trial among 70 patients, demonstrated that prophylactic continuous heparin infusion (100 U/kg/day) can be used safely in children undergoing myeloablative therapy and HSCT. VOD occurred less frequently in the treatment arm $(10 \%)$ compared to the control group $(25.7 \%)(P<0.05)$ [42]. A retrospective study among Korean children undergoing HSCT compared prophylactic UFH infusion versus prostaglandin-E1 administration versus no prophylaxis; while prophylaxis was not associated with a decrease in the overall incidence of VOD, a reduction in the incidence of severe VOD was observed among both treatment groups versus the group which received no prophylaxis [43]. Another retrospective study of 241 children and young adults did not demonstrate a reduction in VOD with heparin prophylaxis [8]. A retrospective analysis of adult patients undergoing HSCT suggested that LMWH was more effective than UFH for the prophylaxis of VOD and that both were independently associated with better outcomes than no prophylaxis [44]. Additionally, a systematic review and meta-analysis of the literature which included 12 studies, found that anticoagulation prophylaxis with LMWH or UFH did not significantly decrease the risk of VOD (pooled relative risk, 0.90; 95\% confidence interval [CI], 0.62-1.29) [45]. There are no controlled studies comparing LMWH with UFH for the prophylaxis of VOD in children. In summary, hep- arin may be considered for prophylaxis against VOD among pediatric HSCT recipients, but further study appears warranted. Whether to use LMWH or UFH may depend on the treating physician's comfort in using these.

\subsection{Heparin combination regimens}

A combination prophylactic regimen of continuous low dose heparin infusion (100 U/kg/day), oral gluatamine $\left(2 \mathrm{~g} / \mathrm{m}^{2} /\right.$ day $)$ and oral ursodiol $(10 \mathrm{mg} / \mathrm{kg} / \mathrm{day})$ from the day of admission to at least 30 days postHSCT has been associated with a low incidence of VOD. In a retrospective analysis of 188 consecutive HSCT patients at a single pediatric center receiving this regimen, only one patient developed VOD [46]. A retrospective analysis of 403 consecutive patients undergoing HSCT suggested that prophylaxis with continuous heparin infusion (100 U/kg/day) and two units of FFP daily was associated with a lower rate of VOD $(5.9 \%)$ compared to infusion of heparin only $(20 \%)$ or no prophylaxis $(15.7 \%)(P<0.01)$. The authors suggest that the combined regimen is beneficial because it minimizes the drop of natural anticoagulants such as protein $\mathrm{C}$ and anti-thrombin which they observed was low on 8th day [47].

\section{4. $F F P$}

Among children and adults undergoing HSCT, the incidence of VOD was lower among patients receiving prophylactic administration of FFP than those who did not. The authors suggested that development of VOD is associated with increased Von Willebrand factor production relative to decreased a thrombospondin type 1 motif, member 13 (ADAMTS13) activity and that FFP administration ameliorates this problem [22].

\subsection{Anti-thrombin}

A prospective case series compared 71 children who did not receive VOD prophylaxis with 91 children who were given pre-emptive anti-thrombin 3 (AT3) replacement to maintain AT3 activity $>70 \%$ [48]. The incidence of VOD was similar in both groups. However, the sensitivity of AT3 levels $<70 \%$ as a diagnostic criteria for VOD was $100 \%$ (95\% CI, 82-100\%) with a specificity of $94 \%$ (95\% CI, 87-97\%) and a likelihood ratio of 15.4 (95\% CI, 7.8-30.4). Patients, who developed VOD, then received a combined regimen of AT3 
replacement and high dose defibrotide (60 mg/day). All of these patients achieved a complete remission of VOD with this regimen.

\subsection{Defibrotide}

A few studies in both children and adults have reported that prophylaxis with defibrotide may be helpful in preventing VOD. A retrospective analysis of 58 patients who received defibrotide prophylaxis without concurrent heparin between 2004 and 2005, found no cases of reported VOD [49]. A comparison of 52 successive patients who underwent HSCT between 1999 and 2000 and received defibrotide prophylaxis at a single center compared to 52 historical controls (1997-1999) who did not, found no cases of VOD in the defibrotide and heparin group compared to $10 / 52$ $(19 \%)$ in the control group, who received heparin prophylaxis only $(P=0.001)$ [50]. A phase 3 open-label, randomized controlled trial conducted between 2006 and 2009 enrolled 356 eligible patients; 22 (12\%) of 180 patients randomly allocated to the defibrotide group had VOD by 30 days after HSCT compared with 35 (20\%) of 176 controls (risk difference $-7.7 \%, 95 \%$ $\mathrm{CI} ;-15.3$ to $-0.1 ; \mathrm{Z}$ test for competing risk analysis $P=0.0488 ; \log$-rank test $P=0.0507)$. One hundred and fifty four $(87 \%)$ of 177 patients in the defibrotide group had adverse events by day 180 compared with 155 (88\%) of 176 controls [51]. Availability of defibrotide is a limiting factor as it is available for prophylaxis in Europe, but not yet in the US where it is available only for specific thrombolytic therapy for treatment of VOD via industry sponsored studies.

\section{Management}

The management of VOD consists mainly of nonspecific supportive therapies as discussed below; specific thrombolytic therapies such as defibrotide and tissue plasminogen activator (TPA) are also discussed. To date, defibrotide appears to be the most promising specific therapy available.

\subsection{Supportive care therapy}

\subsubsection{Monitoring}

Close monitoring of respiratory status and fluid balance is helpful in guiding treatment. We recommend twice daily weight assessments; complete blood cell and serum chemistry evaluations; daily liver function tests and coagulation studies should also be considered. Additionally, more frequent pharmacokinetic drug monitoring and adjustment of medications for associated renal dysfunction should be performed.

\subsubsection{Fluid management and electrolyte issues}

The restriction of fluids and controlled diuresis is critical for patients with VOD as the rate of weight gain has been found to be a predictor for the development of severe VOD [26]. However, HSCT recipients usually require a high volume of intravenous fluids, frequent blood product administration and multiple medications such as cyclosporine, antibiotics, and analgesics, all of which may further impair renal function and contribute to fluid overload despite a low intravascular volume. Once the diagnosis of VOD is confirmed, all attempts should be made to concentrate the medications wherever possible and the total fluid intake should be restricted [52]. Furosemide is usually administered one-two times daily and titrated to achieve baseline weight. Further, it may be necessary to restrict the total fluid intake to $75 \%$ or $50 \%$ of the maintenance in some cases. Chlorothiazide, in addition to furosemide, may be needed to achieve optimal diuresis. Bumetanide may be used in refractory cases. Blood urea nitrogen and serum creatinine levels should be assessed frequently; increasing levels are expected, but must be monitored closely. It is essential that the patient sustains adequate urine output and this must be monitored closely. Correction of hypoalbuminemia with slow infusions of $25 \%$ albumin to maintain a serum albumin of $>3 \mathrm{~g} / \mathrm{dL}$, may help with intravascular depletion and optimize diuresis $[53,54]$. Oliguria and worsening renal function may require continuous renal replacement therapy (CRRT) [55, 56]. In a retrospective series of 26 HSCT recipients with fluid overload, Michael et al. [54] reported no survivors among patients who remained $>10 \%$ fluid overloaded despite aggressive therapy, such as CRRT. Survivors either remained or re-attained $<10 \%$ fluid overload status.

\subsubsection{Transfusion}

Blood and platelets should be transfused to keep the hemoglobin above $7-8 \mathrm{~g} / \mathrm{dL}$ and platelets above $20,000 / \mathrm{mm}^{3}$. Patients with worsening VOD often are refractory to platelet transfusions and a $1 \mathrm{hr}$ post transfusion corrected count increment of $<5000 / \mathrm{mm}^{3}$ may suggest increase consumption of platelets and increased need of transfusions. Continuous platelet 
infusions may be considered if more than 3-4 platelet transfusions are required daily. A higher platelet transfusion parameter $\left(30-50,000 / \mathrm{mm}^{3}\right)$ may be desirable among patients at high risk of bleeding. Vitamin $\mathrm{K}$ and FFP/cryoprecipitate may be infused in patients with abnormal coagulation parameters and low fibrinogen.

\subsubsection{Paracentesis}

Weight gain and ascites are common features of VOD and worsening ascites often contributes to pain and pulmonary dysfunction. If respiratory function continues to deteriorate in spite of supplemental oxygen, fluid restriction and diuresis, then gradual decompression of the tense abdominal ascites by paracentesis is often necessary. This intervention may offer temporary relief of pain and pulmonary dysfunction and is often mistaken for improvement of the VOD. Therapeutic paracentesis can help relieve symptoms in patients with large, tense ascites and may help improve renal function [57]. Usually, an interventional radiology assisted peritoneal drain is placed and slow controlled drainage is started. The peritoneal drain should not be left to drain by gravity, which can lead to potentially fatal hypovolemia from the sudden onset of fluid shifts from the intravascular compartment to the extravascular space (peritoneum). Albumin replacement is usually needed after paracentesis to maintain serum albumin $>3 \mathrm{~g} / \mathrm{dL}$ [53]. While paracentesis may help alleviate pain or dyspnea; however, it is not a specific therapy for VOD.

\subsubsection{Pain}

Most patients are already on opioid infusions for pain due to mucositis or abdominal pain from VOD and the opioids are titrated accordingly. Benzodiazepines should be avoided.

\subsubsection{Organ dysfunction}

Deterioration of renal and respiratory functions may require support in the form of CRRT and assisted ventilation respectively. MOF is usually an indicator of progressive VOD. Patients with the VOD are total body fluid overloaded, but may have decreased intravascular volume. Invasive hemodynamic monitoring usually demonstrates high cardiac output and low systemic vascular resistance [58]. The role of CRRT in the treatment of VOD has been studied. In a retrospective of critically ill pediatric patients who received continuous venovenous hemofiltration $(\mathrm{CVVH})$, increasing degrees of fluid overload prior to the initiation of
CVVH was associated with greater mortality. The degree of fluid overload at CVVH initiation was significantly lower in survivors $(16.4 \pm 13.8 \%)$ compared with non-survivors $(34.0 \pm 21.0 \%)$ [54]. In another report, no survival advantage was found to having a lower percentage of fluid overload prior to the initiation of CRRT, but $81 \%$ of patients in that cohort were mechanically ventilated prior to CRRT [59]. CRRT for patients with VOD who fail to respond to diuretic therapy may also allow down regulation of the inflammatory response by nonselective extracorporeal removal, mainly by absorption of cytokines and other mediators, restoring the hemodynamic and immunologic homeostasis [60-62]. The relative cost of CRRT, and the potential for improved outcome with earlier initiation of CRRT at lesser degrees of fluid overload are factors that may support the early initiation of CRRT in critically ill children with VOD [63]. Special considerations for HSCT patients receiving CRRT include: close monitoring of platelet counts to maintain $>50,000 / \mathrm{mm}^{3}$, dose adjustments of medications such as tacrolimus and voriconazole which may be affected with the initiation and cessation of CRRT, close monitoring and prompt intervention for suspected sepsis, as patients may not mount a febrile response while on the circuit.

\subsection{Specific therapy}

\subsubsection{Defibrotide}

Defibrotide is derived from porcine intestinal mucosa and has antithrombotic and profibrinolytic properties. Though its exact mechanism of action in VOD is not known, it increases endogenous TPA levels, which activates plasminogen to plasmin [64]. Richardson et al. [65] first reported a $42 \%$ response to treatment in 19 patients who met the Baltimore criteria for the diagnosis of VOD in a compassionate use study on patients who had a $40 \%$ probability of developing severe VOD based on the model of Bearman et al. [26]. Subsequently, in a dose finding phase 2 study, $25 \mathrm{mg} / \mathrm{kg} /$ day (in four divided doses) of intravenous defibrotide was compared to a dose of $40 \mathrm{mg} / \mathrm{kg} / \mathrm{day}$; no difference in response or day +100 survival was observed between the two groups ( $46 \%$ and $42 \%$, respectively). Further studies have used $25 \mathrm{mg} / \mathrm{kg} /$ day for treatment of VOD. In a phase 3 trial of defibrotide for treatment of severe VOD diagnosed by the Baltimore criteria, defibrotide therapy was compared to a historical control group. A complete response rate 
of $24 \%$ was observed in those treated with defibrotide versus $9 \%$ in the historical control arm $(P=0.013)$. The day +100 mortality in the defibrotide group was $62 \%$ versus $75 \%(P=0.03)$ in the historical control group [66]. A few retrospective studies in pediatrics have reported similar outcomes. Corbacioglu reported an overall complete response rate of $76 \%$ with $64 \%$ survival at day +100 among children treated for VOD with defibrotide [67]. Similarly, Bulley et al. [68] reported $79 \%$ survival at day +100 with defibrotide use. The European compassionate use defibrotide study by Chopra et al. [69] found a day +100 survival of $43 \%$ and a complete response rate of $36 \%$.

\subsubsection{TPA}

Recombinant TPA (rTPA) has also been used for the treatment of VOD in children and adults. Bearman used rTPA over 2-4 days along with heparin for 10 days in 42 patients and reported a response rate of $29 \%$ and day +100 survival of $24 \%$. Severe bleeding was the cause of death in three patients, and overall, $88 \%$ of the patients had bleeding [70]. In another small pediatric study, Bajwa et al. [10] observed that eight out of 12 patients responded and survived after treatment with rTPA for moderate to severe VOD and only two of the 12 patients had bleeding complications. rTPA is usually given daily at a dose of $0.05 \mathrm{mg} / \mathrm{kg} / \mathrm{hr}$ for $4 \mathrm{hr}$ as an intravenous infusion for 4 days. After 4 days of rTPA therapy, if no improvement is noted, a second course can be given and the dose of rTPA doubled to $0.1 \mathrm{mg} / \mathrm{kg} / \mathrm{hr}$ for $4 \mathrm{hr}$. Heparin is usually administered at a dose of $5 \mathrm{U} / \mathrm{kg} / \mathrm{hr}$ and continued for a total of 10 days. Cesaro et al. [5] in a prospective study treated 12 of the 26 patients with VOD who had reversal of portal venous flow, with rTPA and heparin; four of the 12 patients died from MOF and eight survived. The authors concluded that Doppler US may be helpful in identifying the patients with reversal of portal flow who might benefit from a higher risk therapy with heparin and rTPA. Because of an overall better safety profile currently defibrotide is the preferred for thrombolytic therapy and use of rTPA should be limited to cases who don't respond to defibrotide or if it is not available.

\subsubsection{Steroids}

A prospective study of 48 patients who developed VOD and were treated with $0.5 \mathrm{mg} / \mathrm{kg}$ of methylprednisolone intravenously twice daily for 14 doses revealed a response rate of $63 \%$ and day +100 survival of $58 \%$ [71]. A recent retrospective analysis of 15 pediatric patients who developed VOD at a single institution between 2003 and 2011, found a favorable outcome for six of the nine $(67 \%)$ patients who received methylprednisolone at $500 \mathrm{mg} / \mathrm{m}^{2}$ per dose every $12 \mathrm{hr}$ for six doses [72]. Four of these nine patients also subsequently received defibrotide; however, two of patients died after developing pulmonary hemorrhage. No serious toxicities related to high dose steroid therapy were observed. All five patients who received steroid therapy without defibrotide demonstrated complete resolution of VOD with $100 \%$ survival. However, this has not been studied in a randomized controlled trial.

\subsubsection{Other treatments}

Other therapies or combination of therapies have also been tried in the treatment of VOD. In one prospective series among 14 patients who developed VOD and received a combined regimen of AT3 replacement and high dose defibrotide $(60 \mathrm{mg} /$ day $)$, all patients achieved a complete remission of VOD [48]. Additionally, a report of prostaglandin-E1 infusion (initial dose $0.075 \mu \mathrm{g} / \mathrm{kg} / \mathrm{hr}$ titrated to maximal tolerated dose of $0.3-0.5 \mu \mathrm{g} / \mathrm{kg} / \mathrm{hr}$ ) with low dose heparin for pediatric HSCT recipients with VOD demonstrated resolution of VOD among all three patients with discontinuation of therapy at a median of 14 days (range 9-25 days) [73]. Transvenous intrahepatic portosystemic shunt (TIPS) has also been used among patients with severe VOD to treat the associated portal hypertension. Azoulay et al. [74] reported 10 patients who underwent HSCT, developed VOD and then underwent TIPS. Five patients with rapidly worsening VOD died within 10 days of TIPS, four died subsequently, and only one survived [74]. A few other case reports of successful outcomes after TIPS for VOD have been published $[75,77]$. However, this modality appears to offer only transient improvement and may not improve overall survival. Finally, liver transplantation for patients with VOD following HSCT has been reported. Of the two reported pediatric cases, both have successful outcomes at 17 mo and 9 mo of follow up [78, 79]. Unlike GVHD of the liver, liver transplantation maybe considered for patients with VOD who have an underlying disease associated with a good prognosis such as nonmalignant conditions.

In summary, in spite of decrease in the incidence of infective hepatitis, and monitoring of busulfan levels, VOD still continues to be a potentially fatal complication of HSCT. Defibrotide is known to prevent VOD but 
it is not available for prophylaxis in the United States of America. There are no definitive laboratory markers to help in the diagnosis and grading of severity of VOD is also not clearly defined. Close clinical monitoring, early diagnosis, initiation of supportive care and specific therapy before MOF develops are keys to successful outcome.

\section{References}

[1] Coppell JA, Richardson PG, Soiffer R, Martin PL, Kernan NA, Chen A, et al. Hepatic veno-occlusive disease following stem cell transplantation: Incidence, clinical course, and outcome. Biol Blood Marrow Transplant 2010;16(2):157-68.

[2] Bearman SI. The syndrome of hepatic veno-occlusive disease after marrow transplantation. Blood 1995;85(11):3005-20.

[3] McDonald GB, Sharma P, Matthews DE, Shulman HM, Thomas ED. Venocclusive disease of the liver after bone marrow transplantation: Diagnosis, incidence, and predisposing factors. Hepatology 1984;4(1):116-22.

[4] Jones RJ, Lee KS, Beschorner WE, Vogel VG, Grochow LB, Braine HG, et al. Venoocclusive disease of the liver following bone marrow transplantation. Transplantation 1987;44(6):778-83.

[5] Cesaro S, Pillon M, Talenti E, Toffolutti T, Calore E, Tridello $\mathrm{G}$, et al. A prospective survey on incidence, risk factors and therapy of hepatic veno-occlusive disease in children after hematopoietic stem cell transplantation. Haematologica 2005;90(10):1396-404

[6] Qureshi A, Marshall L, Lancaster D. Defibrotide in the prevention and treatment of veno-occlusive disease in autologous and allogeneic stem cell transplantation in children. Pediatr Blood Cancer 2008;50(4):831-2.

[7] Barker CC, Butzner JD, Anderson RA, Brant R, Sauve RS. Incidence, survival and risk factors for the development of veno-occlusive disease in pediatric hematopoietic stem cell transplant recipients. Bone Marrow Transplant 2003;32(1):79-87.

[8] Reiss U, Cowan M, McMillan A, Horn B. Hepatic venoocclusive disease in blood and bone marrow transplantation in children and young adults: Incidence, risk factors, and outcome in a cohort of 241 patients. J Pediatr Hematol Oncol 2002;24(9):746-50.

[9] Carreras E, Bertz H, Arcese W, Vernant JP, Tomás JF, Hagglund $\mathrm{H}$, et al. Incidence and outcome of hepatic venoocclusive disease after blood or marrow transplantation: A prospective cohort study of the European Group for Blood and Marrow Transplantation. European Group for Blood and Marrow Transplantation Chronic Leukemia Working Party. Blood 1998;92(10):3599-604.

[10] Bajwa RP, Cant AJ, Abinun M, Flood TJ, Hodges S, Hale $\mathrm{JP}$, et al. Recombinant tissue plasminogen activator for treatment of hepatic veno-occlusive disease following bone marrow transplantation in children: Effectiveness and a scoring system for initiating treatment. Bone Marrow Transplant 2003;31(7):591-7.

[11] McDonald GB, Hinds MS, Fisher LD, Schoch HG, Wolford JL, Banaji M, et al. Veno-occlusive disease of the liver and multiorgan failure after bone marrow transplan- tation: A cohort study of 355 patients. Ann Intern Med 1993;118(4):255-67.

[12] Hogan WJ, Maris M, Storer B, Sandmaier BM, Maloney DG, Schoch HG, et al. Hepatic injury after nonmyeloablative conditioning followed by allogeneic hematopoietic cell transplantation: A study of 193 patients. Blood 2004;103(1):78-84.

[13] Slatter MA, Rao K, Amrolia P, Flood T, Abinun M, Hambleton $\mathrm{S}$, et al. Treosulfan-based conditioning regimens for hematopoietic stem cell transplantation in children with primary immunodeficiency: United Kingdom experience. Blood 2011;117(16):4367-75.

[14] Cutler C, Stevenson K, Kim HT, Richardson P, Ho VT, Linden E, et al. Sirolimus is associated with veno-occlusive disease of the liver after myeloablative allogeneic stem cell transplantation. Blood 2008;112(12):4425-31.

[15] Elbahlawan L, McArthur J, Quasney MW, Pei D, Srivastava $\mathrm{K}$, Dahmer MK, et al. Association of IL-1 $\beta$ -511 polymorphism with severe veno-occlusive disease in pediatric-matched allogeneic hematopoietic stem cell transplantation. J Pediatr Hematol Oncol 2012;34(3):175-9

[16] Lennard L, Richards S, Cartwright CS, Mitchell C, Lilleyman JS, Vora A; UK MRC/NCRI Childhood Leukaemia Working Party. The thiopurine methyltransferase genetic polymorphism is associated with thioguanine-related veno-occlusive disease of the liver in children with acute lymphoblastic leukemia. Clin Pharmacol Ther 2006;80(4):375-83.

[17] Cutler C, Kim HT, Ayanian S, Bradwin G, Revta C, Aldridge $\mathrm{J}$, et al. Prediction of veno-occlusive disease using biomarkers of endothelial injury. Biol Blood Marrow Transplant 2010;16(8):1180-5.

[18] Salat C, Holler E, Kolb HJ, Reinhardt B, Pihusch R, Wilmanns $\mathrm{W}$, et al. Plasminogen activator inhibitor-1 confirms the diagnosis of hepatic veno-occlusive disease in patients with hyperbilirubinemia after bone marrow transplantation. Blood 1997;89(6):2184-8

[19] Lee JH, Lee KH, Lee JH, Kim S, Seol M, Park CJ, et al. Plasminogen activator inhibitor-1 is an independent diagnostic marker as well as severity predictor of hepatic veno-occlusive disease after allogeneic bone marrow transplantation in adults conditioned with busulphan and cyclophosphamide. $\mathrm{Br} \mathrm{J}$ Haematol 2002;118(4):1087-94.

[20] Sartori MT, Cesaro S, Peruzzo M, Messina C, Saggiorato $\mathrm{G}$, Calore E, et al. Contribution of fibrinolytic tests to the differential diagnosis of veno-occlusive disease complicating pediatric hematopoietic stem cell transplantation. Pediatr Blood Cancer 2012;58(5):791-7.

[21] Park YD, Yoshioka A, Kawa K, Ishizashi H, Yagi H, Yamamoto Y, et al. Impaired activity of plasma von Willebrand factor-cleaving protease may predict the occurrence of hepatic veno-occlusive disease after stem cell transplantation. Bone Marrow Transplant 2002;29(9):789-94.

[22] Matsumoto M, Kawa K, Uemura M, Kato S, Ishizashi H, Isonishi A, et al. Prophylactic fresh frozen plasma may prevent development of hepatic VOD after stem cell transplantation via ADAMTS13-mediated restoration of von Willebrand factor plasma levels. Bone Marrow Transplant 2007;40(3):251-9.

[23] Iguchi A, Kobayashi R, Kaneda M, Kobayashi K. Plasma protein $\mathrm{C}$ is a useful clinical marker for hepatic veno-occlusive disease (VOD) in stem cell transplantation. Pediatr Blood Cancer 2010;54(3):437-43.

[24] Lee JH, Lee KH, Kim S, Lee JS, Kim WK, Park CJ, et al. Relevance of proteins $\mathrm{C}$ and S, antithrombin III, von Willebrand factor, and factor VIII for the development of hepatic 
veno-occlusive disease in patients undergoing allogeneic bone marrow transplantation: A prospective study. Bone Marrow Transplant 1998;22(9):883-8.

[25] Shulman HM, Hinterberger W. Hepatic veno-occlusive disease-liver toxicity syndrome after bone marrow transplantation. Bone Marrow Transplant 1992;10(3):197-214.

[26] Bearman SI, Anderson GL, Mori M, Hinds MS, Shulman HM McDonald GB. Venoocclusive disease of the liver: Development of a model for predicting fatal outcome after marrow transplantation. J Clin Oncol 1993;11(9):1729-36.

[27] Brown BP, Abu-Yousef M, Farner R, LaBrecque D, Gingrich R. Doppler sonography: A noninvasive method for evaluation of hepatic venocclusive disease. AJR Am J Roentgenol 1990;154(4):721-4

[28] Herbetko J, Grigg AP, Buckley AR, Phillips GL. Venoocclusive liver disease after bone marrow transplantation: Findings at duplex sonography. AJR Am J Roentgenol 1992;158(5):1001-5.

[29] Mahgerefteh SY, Sosna J, Bogot N, Shapira MY, Pappo O, Bloom AI. Radiologic imaging and intervention for gastrointestinal and hepatic complications of hematopoietic stem cell transplantation. Radiology 2011;258(3):660-71.

[30] Hommeyer SC, Teefey SA, Jacobson AF, Higano CS, Bianco JA, Colacurcio CJ, et al. Venocclusive disease of the liver: Prospective study of US evaluation. Radiology 1992;184(3):683-6.

[31] McCarville MB, Hoffer FA, Howard SC, Goloubeva O, Kauffman WM. Hepatic veno-occlusive disease in children undergoing bone-marrow transplantation: Usefulness of sonographic findings. Pediatr Radiol 2001;31(2):102-5.

[32] Lassau N, Auperin A, Leclere J, Bennaceur A, ValteauCouanet D, Hartmann O. Prognostic value of dopplerultrasonography in hepatic veno-occlusive disease. Transplantation 2002;74(1):60-6.

[33] Gauthé M, Bozec L, Bedossa P. Diagnosis of sinusoidal obstruction syndrome by positron emission tomography/computed tomography: Report of two cases treated by defibrotide. Hepatology 2014;60(5):1789-91.

[34] Shin NY, Kim MJ, Lim JS, Park MS, Chung YE, Choi JY, et al. Accuracy of gadoxetic acid-enhanced magnetic resonance imaging for the diagnosis of sinusoidal obstruction syndrome in patients with chemotherapy-treated colorectal liver metastases. Eur Radiol 2012;22(4):864-71.

[35] Kis B, Pamarthi V, Fan CM, Rabkin D, Baum RA. Safety and utility of transjugular liver biopsy in hematopoietic stem cell transplant recipients. J Vasc Interv Radiol 2013;24(1):85-9.

[36] Solomkin JS. Evaluating evidence and grading recommendations: The SIS/IDSA guidelines for the treatment of complicated intra-abdominal infections. Surg Infect (Larchmt) 2010;11(3):269-74

[37] Essell JH, Schroeder MT, Harman GS, Halvorson R, Lew V, Callander N, et al. Ursodiol prophylaxis against hepatic complications of allogeneic bone marrow transplantation. A randomized, double-blind, placebo-controlled trial. Ann Intern Med 1998;128(12 Pt 1):975-81.

[38] Ohashi K, Tanabe J, Watanabe R, Tanaka T, Sakamaki H, Maruta A, et al. The Japanese multicenter open randomized trial of ursodeoxycholic acid prophylaxis for hepatic veno-occlusive disease after stem cell transplantation. Am J Hematol 2000;64(1):32-8.

[39] Ruutu T, Eriksson B, Remes K, Juvonen E, Volin L, Remberger M, et al; Nordic Bone Marrow Transplantation Group.
Ursodeoxycholic acid for the prevention of hepatic complications in allogeneic stem cell transplantation. Blood 2002;100(6):1977-83.

[40] Park SH, Lee MH, Lee H, Kim HS, Kim K, Kim WS, et al. A randomized trial of heparin plus ursodiol vs. heparin alone to prevent hepatic veno-occlusive disease after hematopoietic stem cell transplantation. Bone Marrow Transplant 2002;29(2):137-43

[41] Tay J, Tinmouth A, Fergusson D, Huebsch L, Allan DS Systematic review of controlled clinical trials on the use of ursodeoxycholic acid for the prevention of hepatic venoocclusive disease in hematopoietic stem cell transplantation. Biol Blood Marrow Transplant 2007;13(2):206-17.

[42] Rosenthal J, Sender L, Secola R, Killen R, Millerick M, Murphy L, et al. Phase II trial of heparin prophylaxis for veno-occlusive disease of the liver in children undergoing bone marrow transplantation. Bone Marrow Transplant 1996;18(1):185-91.

[43] Song JS, Seo JJ, Moon HN, Ghim T, Im HJ. Prophylactic lowdose heparin or prostaglandin E1 may prevent severe venoocclusive disease of the liver after allogeneic hematopoietic stem cell transplantation in Korean children. J Korean Med Sci 2006;21(5):897-903.

[44] Simon M, Hahn T, Ford LA, Anderson B, Swinnich D, Baer MR, et al. Retrospective multivariate analysis of hepatic veno-occlusive disease after blood or marrow transplantation: Possible beneficial use of low molecular weight heparin. Bone Marrow Transplant 2001;27(6):627-33.

[45] Imran H, Tleyjeh IM, Zirakzadeh A, Rodriguez V, Khan SP. Use of prophylactic anticoagulation and the risk of hepatic veno-occlusive disease in patients undergoing hematopoietic stem cell transplantation: A systematic review and metaanalysis. Bone Marrow Transplant 2006;37(7):677-86.

[46] Lakshminarayanan S, Sahdev I, Goyal M, Vlachos A, Atlas M, Lipton JM. Low incidence of hepatic veno-occlusive disease in pediatric patients undergoing hematopoietic stem cell transplantation attributed to a combination of intravenous heparin, oral glutamine, and ursodiol at a single transplan institution. Pediatr Transplant 2010;14(5):618-21.

[47] Batsis I, Yannaki E, Kaloyannidis P, Sakellari I, Smias C, Georgoulis I, et al. Veno-occlusive disease prophylaxis with fresh frozen plasma and heparin in bone marrow transplantation. Thromb Res 2006;118(5):611-8.

[48] Haussmann U, Fischer J, Eber S, Scherer F, Seger R, Gungor T. Hepatic veno-occlusive disease in pediatric stem cell transplantation: Impact of pre-emptive antithrombin III replacement and combined antithrombin III/defibrotide therapy. Haematologica 2006;91(6):795-800.

[49] Dignan F, Gujral D, Ethell M, Evans S, Treleaven J, Morgan $\mathrm{G}$, et al. Prophylactic defibrotide in allogeneic stem cell transplantation: Minimal morbidity and zero mortality from veno-occlusive disease. Bone Marrow Transplant 2007;40(1):79-82

[50] Chalandon Y, Roosnek E, Mermillod B, Newton A, Ozsahin $\mathrm{H}$, Wacker $\mathrm{P}$, et al. Prevention of veno-occlusive disease with defibrotide after allogeneic stem cell transplantation. Biol Blood Marrow Transplant 2004;10(5):347-54

[51] Corbacioglu S, Kernan N, Lehmann L, Brochstein J, Revta C, Grupp S, et al. Defibrotide for the treatment of hepatic veno-occlusive disease in children after hematopoietic stem cell transplantation. Expert Rev Hematol 2012;5(3): 291-302. 
[52] Carreras E, Díaz-Beyá M, Rosiñol L, Martínez C, FernándezAvilés F, Rovira M. The incidence of veno-occlusive disease following allogeneic hematopoietic stem cell transplantation has diminished and the outcome improved over the last decade. Biol Blood Marrow Transplant 2011;17(11):1713-20.

[53] Salerno F, Badalamenti S, Incerti P, Tempini S, Restelli B, Bruno $S$, et al. Repeated paracentesis and i.v. albumin infusion to treat 'tense' ascites in cirrhotic patients. A safe alternative therapy. J Hepatol 1987;5(1):102-8.

[54] Michael M, Kuehnle I, Goldstein SL. Fluid overload and acute renal failure in pediatric stem cell transplant patients. Pediatr Nephrol 2004;19(1):91-5.

[55] Sutherland SM, Zappitelli M, Alexander SR, Chua AN, Brophy PD, Bunchman TE, et al. Fluid overload and mortality in children receiving continuous renal replacement therapy: The prospective pediatric continuous renal replacement therapy registry. Am J Kidney Dis 2010;55(2):316-25.

[56] Flores FX, Brophy PD, Symons JM, Fortenberry JD, Chua AN, Alexander SR, et al. Continuous renal replacement therapy (CRRT) after stem cell transplantation. A report from the prospective pediatric CRRT Registry Group. Pediatr Nephrol 2008;23(4):625-30.

[57] Saudan P, Martin PY, Jaques D, Schonenberg P, Helg C, Favre H. Paracentesis for acute renal failure caused by hepatic venoocclusive disease. Lancet 1994;343(8893):365.

[58] Crawford SW, Hickman RO, Ulz L, O'Quin T, Wong R, McDonald GB. Use of the Hickman-Crawford critical care catheter in marrow transplant recipients: A pulmonary artery catheter-adaptable central venous access. Crit Care Med 1994;22(2):347-52.

[59] Rajasekaran S, Jones DP, Avent Y, Shaffer ML, Elbahlawan $\mathrm{L}$, Henderson N, et al. Outcomes of hematopoietic stem cell transplant patients who received continuous renal replacement therapy in a pediatric oncology intensive care unit. Pediatr Crit Care Med 2010;11(6):699-706.

[60] DiCarlo JV, Alexander SR, Agarwal R, Schiffman JD. Continuous veno-venous hemofiltration may improve survival from acute respiratory distress syndrome after bone marrow transplantation or chemotherapy. J Pediatr Hematol Oncol 2003;25(10):801-5.

[61] Di Carlo JV, Alexander SR. Hemofiltration for cytokinedriven illnesses: The mediator delivery hypothesis. Int J Artif Organs 2005;28(8):777-86.

[62] DiCarlo J, Agarwal-Hashmi R, Shah A, Kim P, Craveiro L, Killen R, et al. Cytokine and chemokine patterns across 100 daysafter hematopoietic stem cell transplantation in children. Biol Blood Marrow Transplant 2014;20(3):361-9.

[63] Goldstein SL, Currier H, Graf CD, Cosio CC, Brewer ED, Sachdeva R. Outcome in children receiving continuous venovenous hemofiltration. Pediatrics 2001;107(6):1309-12.

[64] Falanga A, Vignoli A, Marchetti M, Barbui T. Defibrotide reduces procoagulant activity and increases fibrinolytic properties of endothelial cells. Leukemia 2003;17(8): 1636-42.

[65] Richardson PG, Elias AD, Krishnan A, Wheeler C, Nath R, Hoppensteadt D, et al. Treatment of severe veno-occlusive disease with defibrotide: Compassionate use results in response without significant toxicity in a high-risk population. Blood 1998;92(3):737-44.

[66] Richardson PG, Ho VT, Giralt S, Arai S, Mineishi S, Cutler C, et al. Safety and efficacy of defibrotide for the treatment of severe hepatic veno-occlusive disease. Ther Adv Hematol 2012;3(4):253-65.

[67] Corbacioglu S, Greil J, Peters C, Wulffraat N, Laws HJ, Dilloo $\mathrm{D}$, et al. Defibrotide in the treatment of children with veno-occlusive disease (VOD): A retrospective multicentre study demonstrates therapeutic efficacy upon early intervention. Bone Marrow Transplant 2004;33(2):189-95.

[68] Bulley SR, Strahm B, Doyle J, Dupuis LL. Defibrotide for the treatment of hepatic veno-occlusive disease in children. Pediatr Blood Cancer 2007;48(7):700-4.

[69] Chopra R, Eaton JD, Grassi A, Potter M, Shaw B, Salat C, et al. Defibrotide for the treatment of hepatic veno-occlusive disease: Results of the European compassionate-use study. $\mathrm{Br}$ J Haematol 2000;111(4):1122-9.

[70] Bearman SI, Lee JL, Barón AE, McDonald GB. Treatment of hepatic venocclusive disease with recombinant human tissue plasminogen activator and heparin in 42 marrow transplant patients. Blood 1997;89(5):1501-6.

[71] Al Beihany A, Al Omar H, Sahovic E, Chaudhri N, Al Mohareb F, Al Sharif F, et al. Successful treatment of hepatic veno-occlusive disease after myeloablative allogeneic hematopoietic stem cell transplantation by early administration of a short course of methylprednisolone. Bone Marrow Transplant 2008;41(3):287-91.

[72] Myers KC, Lawrence J, Marsh RA, Davies SM, Jodele S. High-dose methylprednisolone for veno-occlusive disease of the liver in pediatric hematopoietic stem cell transplantation recipients. Biol Blood Marrow Transplant 2013;19(3):500-3.

[73] Schlegel PG, Haber HP, Beck J, Krümpelmann S, Handgretinger R, Bader P, et al. Hepatic veno-occlusive disease in pediatric stem cell recipients: Successful treatment with continuous infusion of prostaglandin E1 and low-dose heparin. Ann Hematol 1998;76(1):37-41.

[74] Azoulay D, Castaing D, Lemoine A, Hargreaves GM, Bismuth H. Transjugular intrahepatic portosystemic shunt (TIPS) for severe veno-occlusive disease of the liver following bone marrow transplantation. Bone Marrow Transplant 2000;25(9):987-92.

[75] de la Rubia J, Carral A, Montes H, Urquijo JJ, Sanz GF, Sanz MA. Successful treatment of hepatic veno-occlusive disease in a peripheral blood progenitor cell transplant patient with a transjugular intrahepatic portosystemic stent-shunt (TIPS). Haematologica 1996;81(6):536-9.

[76] Smith FO, Johnson MS, Scherer LR, Faught P, Breitfeld PP, Albright E, et al. Transjugular intrahepatic portosystemic shunting (TIPS) for treatment of severe hepatic veno-occlusive disease. Bone Marrow Transplant 1996;18(3):643-6.

[77] Fried MW, Connaghan DG, Sharma S, Martin LG, Devine $\mathrm{S}$, Holland $\mathrm{K}$, et al. Transjugular intrahepatic portosystemic shunt for the management of severe venoocclusive disease following bone marrow transplantation. Hepatology 1996;24(3):588-91.

[78] Kim ID, Egawa H, Marui Y, Kaihara S, Haga H, Lin YW, et al. A successful liver transplantation for refractory hepatic venoocclusive disease originating from cord blood transplantation. Am J Transplant 2002;2(8):796-800.

[79] Bunin N, Leahey A, Dunn S. Related donor liver transplant for veno-occlusive disease following T-depleted unrelated donor bone marrow transplantation. Transplantation 1996;61(4):664-6. 